\title{
Applicability of Commercially Available ELISA Kits for the Quantification of Faecal Immunoreactive Corticosterone Metabolites in Mice
}

\author{
KLAS S.P. ABELSON, OTTO KALLIOKOSKI, ANNE CHARLOTTE TEILMANN and JANN HAU \\ Department of Experimental Medicine, Faculty of Health and Medical Sciences, \\ University of Copenhagen, Copenhagen, Denmark
}

\begin{abstract}
Background: Commercially available ELISA kits are popular among investigators that quantify faecal corticosterone or cortisol metabolites (FCM) for stress assessment in animals. However, in faeces, these assays mainly detect immunoreactive glucocorticoid metabolites. Since different assays contain antibodies of different origin, the detection level and cross-reactivity towards different metabolites and other steroids differ considerably between assays. Thus, the validity of one assay for FCM quantification in stress assessment is not necessarily the same for another assay. Materials and Methods: The present study was designed to investigate corticosterone (CORT) in serum and FCM levels in faeces of laboratory mice, as quantified in four different ELISA kits (DRG EIA-4164, Demeditec DEV9922, Enzo ADI-900-097 and Cayman EIA kit 500655). Assay kits were chosen based on the origin of the antibody, detection level and variation in cross-reactivity. Results: As expected, all four assay kits could detect higher serum CORT levels in mice treated with adrenocorticotropic hormone (ACTH), compared to untreated mice. Unexpectedly though, the measured concentration of serum CORT differed significantly between assays, in both groups of mice. In faecal samples, there was no consistent positive correlation between the levels detected in the four assays and the measured concentration of FCM also differed between assays. Conclusion: Whereas commercially available CORT ELISAs are frequently successfully used for FCM quantification, validation of the
\end{abstract}

This article is freely accessible online.

Correspondence to: Klas Abelson, Associate Professor, Ph.D., Department of Experimental Medicine, Blegdamsvej 3B, DK2200 Copenhagen N, Denmark. Tel: +45 30507813, e-mail: klasab@sund.ku.dk

Key Words: Mice, stress, immune assays, faecal corticosterone metabolites. assays is necessary as all assays do not work well under all circumstances. In this study, the ELISAs could determine relative differences in serum CORT levels and FCM levels between samples; however, the fidelity of the measurements to the true concentrations was low.

Recognition and assessment of physiological stress is essential in the care of, and experimentation on, laboratory mice, since stress may have a considerable negative impact on the welfare of animals, as well as on experimental data (1). A common way of assessing stress is to measure the concentration of corticosterone (CORT) in blood. Corticosterone is increased in blood within a few minutes during an acute stress response and, thus, measuring the blood concentration of CORT is a well-validated method for determining acute stress (2-7). However, a blood sample gives only the momentary concentration and, therefore, merely reflects the stress response at that very instant. The blood sampling procedure itself is also problematic, since it is invasive and requires certain form of restraint, which causes stress and trauma to the animal $(4,5)$. To circumvent these issues, faeces can be collected from the mouse cage and faecal CORT metabolites (FCM) can be extracted. The FCM levels reflect an average of the preceding CORT levels in the blood during a chosen time period (8). Furthermore, invasive procedures on the animals are avoided, since collection of faecal pellets can be performed with minimal or no interference.

Many studies, among them certain performed in our laboratory, have applied commercially available enzymelinked immunosorbent assays (ELISAs) for the quantification of FCM for stress assessment in several animal species, including laboratory mice (3-5, 9-12). However, such assays are generally designed for measuring serum CORT in its native form, with the content of native CORT being very low in faecal samples (13). Thus, in faeces, these assays mainly detect a panorama of immunoreactive CORT metabolites, which in many cases 
Table I. Overview of ELISAs applied in the study.

\begin{tabular}{|c|c|c|c|}
\hline Assay & Antibody & Detection level & Cross-reactivity $(>0.1 \%)$ \\
\hline DRG EIA-4164 & Polyclonal (species unspecified) & $<1.6 \mathrm{nmol} / \mathrm{l}(553 \mathrm{pg} / \mathrm{ml})$ & $\begin{array}{c}\text { Progesterone } 7.4 \% \\
\text { Deoxycorticosterone } 3.4 \% \\
\text { 11-dehydrocorticosterone } 1.6 \% \\
\text { Cortisol } 0.3 \% \\
\text { Pregnenolone } 0.3 \%\end{array}$ \\
\hline Demeditec DEV9922 & Rabbit polyclonal & $1.6 \mathrm{nmol} / \mathrm{l}(553 \mathrm{pg} / \mathrm{ml})$ & $\begin{array}{c}\text { 11-deoxycorticosterone } 2.4 \% \\
\text { Progesterone } 0.7 \% \\
\text { Cortisol } 0.3 \% \\
\text { Aldosterone } 0.2 \%\end{array}$ \\
\hline Enzo ADI-900-097 & Sheep polyclonal & $26.99 \mathrm{pg} / \mathrm{ml}(0.078 \mathrm{nmol} / \mathrm{l})$ & $\begin{array}{c}\text { Deoxycorticosterone } 28,6 \% \\
\text { Progesterone } 1.7 \% \\
\text { Tetrahydrocorticosterone } 0.28 \% \\
\text { Aldosterone } 0.18 \% \\
\text { Testosterone } 0.13 \%\end{array}$ \\
\hline Cayman EIA 500655 & Sheep polyclonal & $30 \mathrm{pg} / \mathrm{ml}(0.087 \mathrm{nmol} / \mathrm{l})$ & $\begin{array}{c}\text { 11-deoxycorticosterone } 11 \% \\
\text { 11-dehydrocorticosterone } 7 \% \\
\text { Progesterone } 0.31 \% \\
\text { Cortisol } 0.17 \%\end{array}$ \\
\hline
\end{tabular}

Data are based on information reported by the manufacturers.

accurately reflect the preceding levels of serum CORT (1416). However, since different assays utilise antibodies of different origin and specificity, the detection level and crossreactivity towards different metabolites and other, unrelated, steroids differ considerably between assays. Thus, the validity of one assay for FCM quantification in stress assessment is not necessarily the same for another assay.

In order to elucidate this matter, we designed the present study to investigate CORT in serum and FCM levels in faeces of laboratory mice, as quantified in four different ELISA kits (DRG EIA-4164, Demeditec DEV9922, Enzo ADI-900-097 and Cayman EIA kit 500655). Assay kits were chosen based on the origin of antibody, reported detection level and variation in cross-reactivity to different metabolites and other steroids (see Table I for details). The DRG assay has been extensively used and validated in our laboratory $(14,15)$. Therefore, we used this assay as the reference assay to compare the other assays with.

The null hypothesis was that all four assays would detect the same levels of serum CORT and FCM from each unique sample. The aim of the study was to generate information that can be useful in the interpretation of data from faecal samples during stress assessment in laboratory mice.

\section{Materials and Methods}

Animals. All animal housing and experimental protocols in the present study were approved by the Danish Animal Experiments Inspectorate (license no. 2012-DY-2934-00018) under the Ministry of Environment and Food and after review of the local animal welfare body of the faculty. The animal use was, thus, in accordance to Danish legislation on experimental animals and to Directive 2010/63/EU on the Protection of Animals used for Scientific Purposes.

Twenty-four male outbred BomTac:NMRI mice from Taconic, Ry, Denmark, were used in the study.

Housing conditions. The animals were housed in an animal facility fully accredited by the Association for the Assessment and Accreditation of Laboratory Animal Care (AAALAC) in accordance with the Guide for Care and Use of Laboratory Animals (17) and with Directive 2010/63/EU (18). Before the experiments, the mice were single-housed in individually ventilated Macrolone type III cages (800 $\mathrm{cm}^{2}$ floor area; $15 \mathrm{~cm}$ high) for one week prior to experimentation. Wooden chips (Tapvei Oy., Kortteinen, Finland) were used as bedding material. Bite bricks (Tapvet ${ }^{\circledR}$, Kortteinen, Finland), Enviro-dri ${ }^{\circledR}$ nesting materials (Shepherd Specialty papers, Quakertown, PA, USA) and cardboard houses (Brogaarden, Gentofte, Denmark) were used for environmental enrichment. A diurnal rhythm was maintained with a 12:12 hour light-dark cycle, with artificial light from 06:00. Cage temperature was kept at $22^{\circ} \mathrm{C}$, relative humidity at $50 \%$ and the air was exchanged 75 times per $\mathrm{h}$. Mice were fed ad libitum with Altromin 1319 pellets (Brogaarden, Gentofte, Denmark) and acidified tap water was available at all times.

Study design. Mice were divided into four groups with six mice in each. Group size was based on a power analysis (19) where a twofold increase in mean FCM levels after adrenocorticotropic hormone (ACTH) injection was considered biologically relevant, based on previous studies (14-16). The standard deviation was estimated to be approximately 0.75 times the mean, the level of significance $(\alpha)$ was set to $5 \%$ and the desired power (1- $\beta$ ) was set to $80 \%$.

At 9 a.m., mice in all groups were placed in a clean cage to enable sampling of faecal pellets dropped after the experiment started. Mice in Group 1 and 3 were left alone until the subsequent 

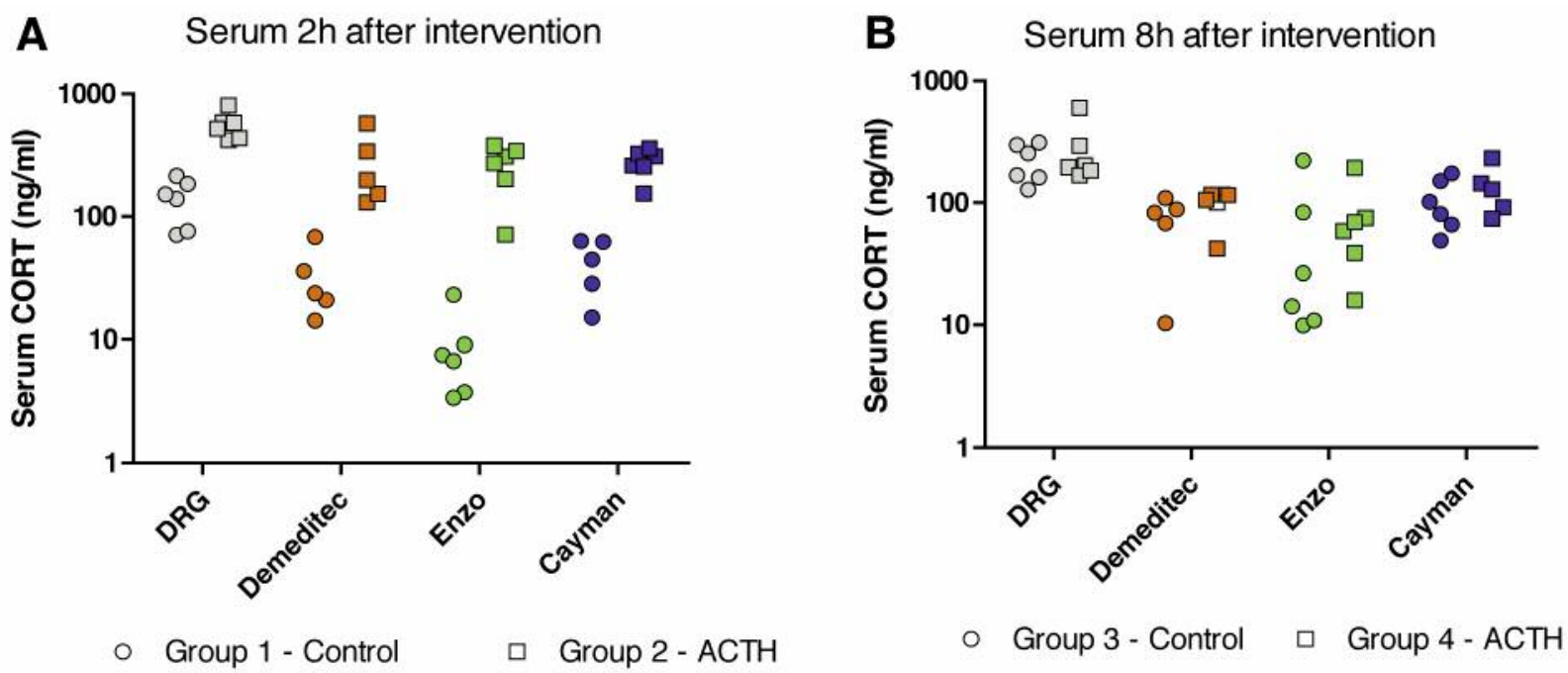

Figure 1. Concentration of corticosterone (CORT) in serum samples $(\mathrm{ng} / \mathrm{ml})$ in non-treated and adrenocorticotropic hormone (ACTH)-treated mice as quantified in the four ELISAs. Data are presented as individual data points for each animal and assay. A: $2 \mathrm{~h}$ and B: $8 \mathrm{~h}$ after intervention with mice in the ACTH groups.

blood and faecal sampling. Mice in Group 3 and 4 were injected subcutaneously with $2 \mathrm{mg} / \mathrm{kg}$ ACTH (ACTH 1-24; PolyPeptide Laboratories, Strasbourg, France) in $0.25 \mathrm{ml}$ PBS. At 11 a.m. (2 h after start), blood and faeces were collected from mice in Group 1 and 2 and, at 17 p.m. (8 h after start), blood and faeces were collected from mice in Group 3 and 4.

Blood and faecal sampling. At the time of sampling, mice were concussed and decapitated; blood was collected in Eppendorf tubes. The procedure was completed within 30 seconds. Blood was left to coagulate in a refrigerator for $45 \mathrm{~min}$, followed by centrifugation for $10 \mathrm{~min}$, in order to obtain serum. Serum was stored at $-20^{\circ} \mathrm{C}$ until analysis. After blood sampling, the bedding material from the cage was collected, whereafter all faecal pellets in the cage were gathered and analysed for faecal corticosteroid metabolites.

Enzyme-linked immunosorbent assays (ELISAs). Four different ELISA kits were used in the study. Each serum and faecal extract sample was analysed in parallel in four different commercially available ELISA kits, namely DRG EIA-4164 (DRG Diagnostics, Marburg, Germany), Demeditec DEV9922 (Demeditec, KielWellsee, Germany), Enzo ADI-900-097 (Enzo Life Sciences, Plymoth meeting, PA, USA) and Cayman EIA kit 500655 (Cayman Chemical Company, Ann Arbor, MI, USA), according to the manufacturers' instructions. Assays were chosen based on origin of antibody (sheep or rabbit IgG), detection level $(25-500 \mathrm{pg} / \mathrm{ml})$ and variation in cross-reactivity profile (see Table I for details).

Quantification of CORT and immunoreactive CORT metabolites. Serum samples from each individual mouse were thawed and tested for CORT concentration in all the four different ELISA kits, in accordance with the manufacturers' instructions. Faecal samples were thawed and faecal CORT and FCM were extracted as previously described $(3,14,15)$. In brief, FCM were extracted by

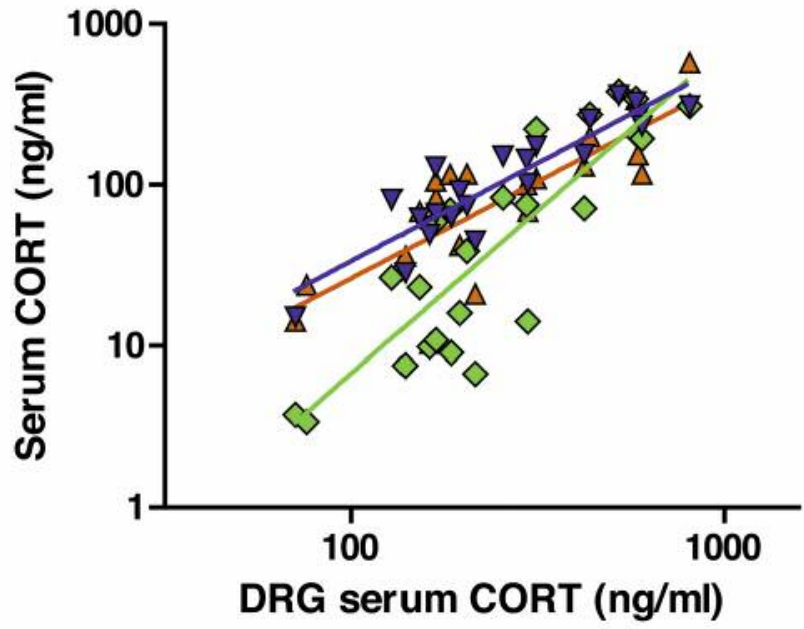

\section{$\Delta$ Demeditec $\diamond$ Enzo $\nabla$ Cayman}

Figure 2. Concentration of corticosterone (CORT) in serum samples $(\mathrm{ng} / \mathrm{ml})$ detected by the DRG assay compared to the concentration in the other three assays. Data are presented as individual data points for each animal and assay. Coloured lines represent the linear regression.

incubating faeces in $96 \%$ ethanol overnight at a ratio of $5 \mathrm{ml}$ ethanol per gram faeces. The homogenate was centrifuged at 3,000 $\times g$ in a Labogene Scanspeed 1236R centrifuge (Labogen A/S, Lynge, Denmark) for $20 \mathrm{~min}$, the supernatant was decanted and the pellet discarded. A $1-\mathrm{ml}$ aliquot of the supernatant was further centrifuged at $10,000 \times g$ for $15 \mathrm{~min}$ in a table top centrifuge (Eppendorf 5415D; Eppendorf AG, Hamburg, Germany). A volume 


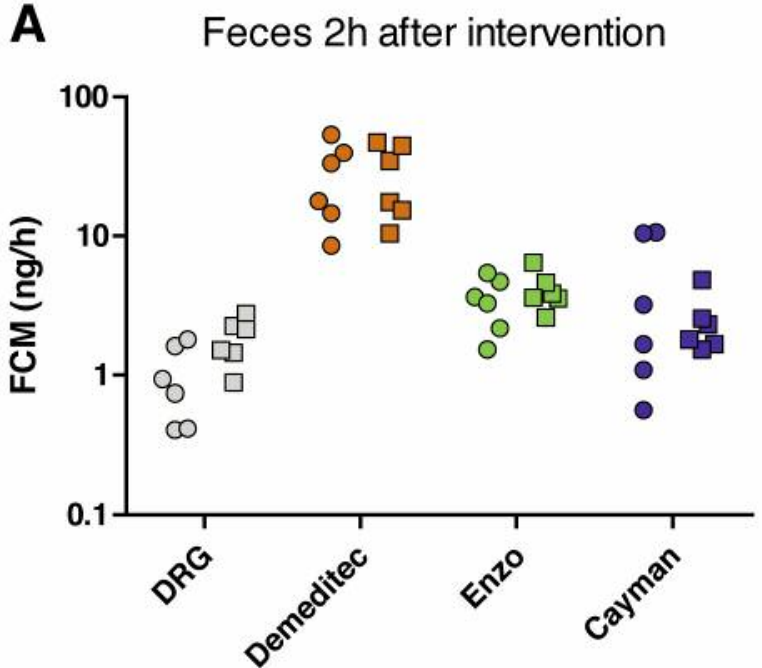

○ Group 1 - Control $\square$ Group 2 - ACTH
B Feces 8h after intervention

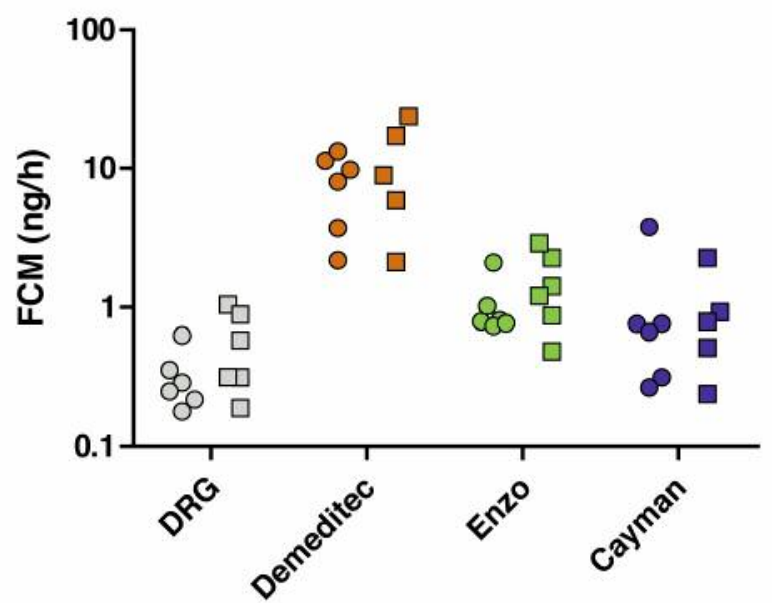

○ Group 3 - Control $\square$ Group 4 - ACTH

Figure 3. Levels of immunoreactive faecal corticosterone metabolites (FCM) in faecal samples (expressed as ng excreted per h) in non-treated and adrenocorticotropic hormone (ACTH)-treated mice as quantified in the four ELISAs. Data are presented as individual data points for each animal and assay. A: $2 \mathrm{~h}$ and $B: 8 \mathrm{~h}$ after intervention with mice in the ACTH groups.

of $200 \mu \mathrm{l}$ of the supernatant was recovered with a pipette while carefully avoiding aspirating any pelleted material and evaporated in a Genevac EZ-2 evaporator (Genevac Ltd., Ipswich, UK). The crystalized material was re-suspended in $200 \mu \mathrm{l}$ assay buffer and analysed as described above.

Statistical analysis. All graphs and statistical calculations were performed in GraphPad Prism 5.0 (GraphPad Inc. La Jolla, CA, USA). Serum CORT concentrations $(\mathrm{ng} / \mathrm{ml})$ and FCM levels (excreted $\mathrm{ng} / \mathrm{h}$ ) were log-transformed and compared with a two-way analysis of variance (ANOVA) with Bonferroni's post-hoc test. Treatment and assay were set as variables. Furthermore, linear regression was performed for all values obtained in the Demeditec, Enzo and Cayman assays in relation to the DRG assay.

\section{Results}

Serum CORT. The serum CORT concentrations detected in the four assays are shown in Figure 1. All four assays could detect significantly higher serum CORT levels in mice treated with ACTH, compared to untreated mice, $2 \mathrm{~h}$ after intervention $(p<0.001)$, as determined with a two-way ANOVA with Bonferroni's post-hoc test. The same test also showed that the measured concentration of serum CORT differed significantly between assays $(p<0.0001)$, for both groups of mice.

The serum CORT levels detected in the DRG assay were compared to the levels in the three other assays using linear regressions (Figure 2). All three assays were positively correlated with the DRG kit where the Demeditec assay had

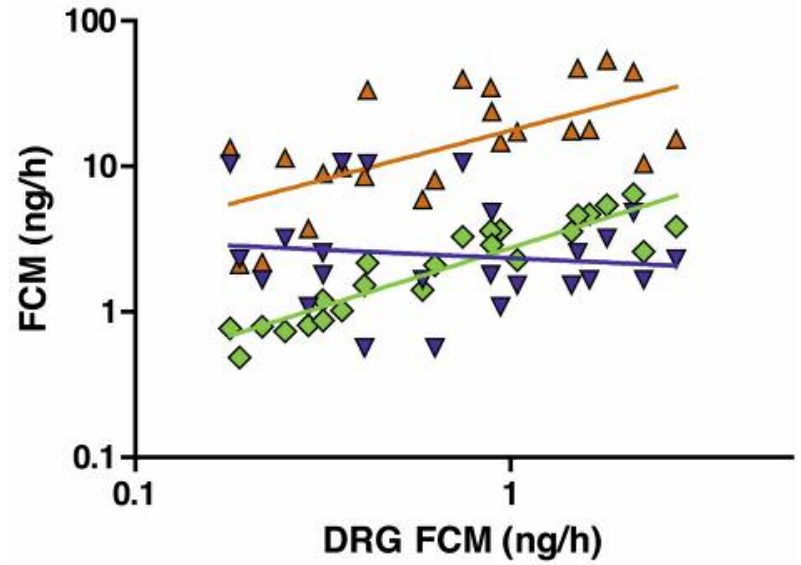

\section{$\Delta$ Demeditec $\diamond$ Enzo $\nabla$ Cayman}

Figure 4. Levels of immunoreactive faecal corticosterone metabolites (FCM) in faecal samples (expressed as ng excreted per h) detected by the DRG assay compared to the concentration in the other three assays. Data are presented as individual data points for each animal and assay. Coloured lines represent the linear regression.

a slope of $1.21 \pm 0.21$, which was significantly different from $0(p<0.0001)$, and the goodness of fit $\left(\mathrm{r}^{2}\right)$ was 0.64 . The Enzo assay had a slope of 2.02 $\pm 0.25(p<0.0001)$ and an $\mathrm{r}^{2}$ of 0.74. The Cayman assay had a slope of $1.22 \pm 0.1251$ $(p<0.0001)$ and an $r^{2}$ of 0.83 . 
Faecal CORT metabolites. The FCM levels detected in the four assays are shown in Figure 3. There was no significant effect of the ACTH treatment on the FCM levels. However, similar to the serum concentrations, there was a significant difference in FCM between the four assays, as determined with the twoway ANOVA $(p<0.0001)$, in both groups of mice.

The FCM levels detected in the DRG assay was compared to the levels in the three other assays with linear regression (Figure 4). Here, all assays, except for Cayman, were positively correlated with the DRG kit. The Demeditec assay had a slope of $0.68 \pm 0.18$ (significantly different from 0 ; $p<0.005)$ and a goodness of fit $\left(\mathrm{r}^{2}\right)$ of 0.40 . The Enzo assay had a slope of $0.81 \pm 0.07(p<0.0001)$ and an $r^{2}$ of 0.84 . The Cayman assay had a slope of $-0.12 \pm 0.21$ (not significantly different from $0 ; p=0.59$ ) and an $\mathrm{r}^{2}$ of 0.01 .

\section{Discussion}

The present study investigated the suitability of using different commercially available ELISA kits for quantifying the levels of FCM in relation to the levels of CORT detected in serum.

As expected, all four assays could detect higher serum CORT levels in mice treated with ACTH, compared to untreated mice. Furthermore, a higher level of serum CORT in non-ACTH-treated mice was seen in the evening $(8 \mathrm{~h}$ after intervention), which follows the natural circadian rhythm of mice $(20,21)$. Unexpectedly though, the measured concentration of serum CORT differed significantly between assays, for both groups of mice. On the other hand, in all assays the relative difference between treated and non-treated mice followed the same pattern; all assays were positively correlated with the DRG assay. This means that the CORT assays tested in this study are, as expected, fully applicable in order to distinguish between high and low levels of serum CORT. However, caution must be taken when discussing absolute concentrations of CORT, since the ELISAs appear to deviate from the true serum values by some margin.

In faecal samples, similar to serum samples, the actual concentration of FCM measured also differed unexpectedly between assays. It was expected that the FCM values would be higher 8 hours after ACTH injection, since this is the approximate lag time $(16,22,23)$ from adrenal release to subsequent excretion in faeces of CORT for rats and mice. However, in a recent study from our laboratory, we discovered that a single injection of $2 \mathrm{mg} / \mathrm{kg}$ ACTH, which was used in the present study, is not sufficient to induce a satisfactory increase in blood CORT that causes a significantly elevated FCM level in faeces but that repeated injections of this dose are necessary (15). Thus, we were unable to confirm that elevated serum levels of CORT actually do lead to elevated levels in FCM in the present study. However, this was not the main scope of the present study and, since we have previously presented evidence of the applicability of FCM (15), we chose not to proceed with this matter. As expected though, lower levels were observed in non-ACTH-treated mice in the evening ( $8 \mathrm{~h}$ after intervention). This was expected since the FCM rhythm is inverted compared to serum levels, following the lag time discussed above.

Commercially available immunoassays may be problematic for FCM quantification, since they detect immunoreactive CORT metabolites in faeces, and the precise composition of metabolites in faeces is rarely known and is likely to vary between sex and between strains of mice, as well as between different experimental conditions. Therefore, other approaches have been suggested for quantifying FCM in an appropriate manner. It has, for instance, been suggested that the CORT metabolite $5 \alpha$-pregnane-3 $\beta, 11 \beta, 21$-triol-20one measured in faeces is predictive of preceding serum CORT levels in mice $(13,24)$. However, the assay for $5 \alpha-$ pregnane-3 $\beta, 11 \beta, 21$-triol-20-one is not commercially available and, thus, needs to be set up in the laboratory. Since other studies have demonstrated that quantification of a number of immunoreactive metabolites is indeed representative of preceding CORT levels both in rats and mice, this method should be considered just as reliable, provided that it is properly validated. The results presented in this study illustrate the importance of assay validation when using FCM for investigating adrenocortical activity in mice and that all assays applied need to be validated before any interpretation can be done, regardless of whether a set of immunoreactive CORT metabolites or a specific metabolite is being used.

In conclusion, commercially available corticosterone ELISAs are useful for FCM quantification in most cases; however, validation of an assay is necessary before it can be applied in stress assessment. Furthermore, the ELISA can accurately determine relative differences in serum CORT and FCM levels between samples but the precision in determining the actual value of the concentration is low.

\section{Acknowledgements}

The Authors wish to thank Trine Marie Ahlman Glahder and Helle Porsdal for their invaluable technical assistance.

\section{References}

1 Morton DB and Hau J: Welfare assessment and humane endpoints. In: Handbook of Laboratory Animal Science: Volume 1 - Essential Principles and Practices (Hau J, Schapiro SJ eds.). Boca Raton: CRC Press, pp. 535-572, 2011.

2 Azpiroz A, Fano E, Garmendia L, Arregi A, Cacho R, Beitia G and Brain PF: Effects of chronic mild stress (CMS) and imipramine administration, on spleen mononuclear cell proliferative response, serum corticosterone level and brain norepinephrine content in male mice. Psychoneuroendocrinol 24: 345-361, 1999. 
3 Sundbom R, Jacobsen KR, Kalliokoski O, Hau J and Abelson $\mathrm{KS}$ : Post-operative corticosterone levels in plasma and feces of mice subjected to permanent catheterization and automated blood sampling. In Vivo 25: 335-342, 2011.

4 Teilmann AC, Kalliokoski O, Sorensen DB, Hau J and Abelson KS: Manual versus automated blood sampling: impact of repeated blood sampling on stress parameters and behavior in male NMRI mice. Lab Anim 48: 278-291, 2014.

5 Teilmann AC, Nygaard MA, Holst B, Hau J, Rozell B and Abelson KS: Physiological and pathological impact of blood sampling by retro-bulbar sinus puncture and facial vein phlebotomy in laboratory mice. PLoS One 9: e113225, 2014.

6 Tuli JS, Smith JA and Morton DB: Effects of acute and chronic restraint on the adrenal gland weight and serum corticosterone concentration of mice and their faecal output of oocysts after infection with Eimeria apionodes. Res Vet Sci 59: 82-86, 1995.

7 Woodman DD: The adrenal glands. In: Laboratory Animal Endocrinology: Hormonal Action, Control Mechanism and Interactions with Drugs. Chichester: John Wiley and Sons Ltd., pp. 253-286, 1997.

8 Goymann W: Noninvasive monitoring of hormones in bird droppings: physiological validation, sampling, extraction, sex differences, and the influence of diet on hormone metabolite levels. Ann NY Acad Sci 1046: 35-53, 2005.

9 Jacobsen KR, Fauerby N, Raida Z, Kalliokoski O, Hau J, Johansen FF and Abelson KS: Effects of buprenorphine and meloxicam analgesia on induced cerebral ischemia in C57BL/6 male mice. Comp Med 63: 105-113, 2013.

10 Jacobsen KR, Kalliokoski O, Teilmann AC, Hau J and Abelson KS: The effect of isoflurane anaesthesia and vasectomy on circulating corticosterone and ACTH in BALB/c mice. Gen Comp Endocrinol 179: 406-413, 2012.

11 Teilmann AC, Jacobsen KR, Kalliokoski O, Hansen AK, Hau J and Abelson KS: The effect of automated blood sampling on corticosterone levels, body weight and daily food intake in permanently catheterized male BALB/c mice. In Vivo 26: 577$582,2012$.

12 Teilmann AC, Kalliokoski O, Jacobsen KR, Hau J and Abelson KS: Impact of heparin and short term anesthesia on the quantification of cytokines in laboratory mouse plasma. Acta Vet Scand 56: 33, 2014.

13 Touma C, Sachser N, Mostl E and Palme R: Effects of sex and time of day on metabolism and excretion of corticosterone in urine and feces of mice. Gen Comp Endocrinol 130: 267-278, 2003.

14 Kalliokoski O, Jacobsen KR, Teilmann AC, Hau J and Abelson KS: Quantitative effects of diet on fecal corticosterone metabolites in two strains of laboratory mice. In Vivo 26: 213 $221,2012$.
15 Kalliokoski O, Teilmann AC, Abelson KS and Hau J: The distorting effect of varying diets on fecal glucocorticoid measurements as indicators of stress: a cautionary demonstration using laboratory mice. Gen Comp Endocrinol 211: 147-153, 2015.

16 Siswanto H, Hau J, Carlsson HE, Goldkuhl R and Abelson KSP: Corticosterone concentrations in blood and excretion in faeces after ACTH administration in male Sprague-Dawley rats. In Vivo 22: 435-440, 2008.

17 Institute of Laboratory Animal Research: Guide for the Care and Use of Laboratory Animals. Washington DC: The National Academies Press, 2011.

18 Directive 2010/63 of the European Parliament and of the Council of 22 September 2010 on the protection of animals used for scientific purposes. Official Journal of the European Union L246: 33-77, 2010.

19 Festing MFW and Weigler BJ: Experimental design and statistical analysis. In: Handbook of laboratory animal science, vol. 1. Essential principles and practices (Hau J, van Hoosier Jr. GL eds.). Boca Raton: CRC Press, pp. 327-350, 2003.

20 Barriga C, Martin MI, Tabla R, Ortega E and Rodriguez AB: Circadian rhythm of melatonin, corticosterone and phagocytosis: effect of stress. J Pineal Res 30: 180-187, 2001.

21 Kannan Y: Neuroendocrine-immune network in stress. In: Handbook of Experimental Animals - The Laboratory Mouse (Hedrich HJ, Bullock G eds.). London: Elsevier, pp. 301-307, 2004.

22 Kalliokoski O, Hau J, Jacobsen KR, Schumacher-Petersen C and Abelson KS: Distribution and time course of corticosterone excretion in faeces and urine of female mice with varying systemic concentrations. Gen Comp Endocrinol 168: 450-454, 2010.

23 Thanos PK, Cavigelli SA, Michaelides M, Olvet DM, Patel U, Diep MN and Volkow ND: A non-invasive method for detecting the metabolic stress response in rodents: Characterization and disruption of the circadian corticosterone rhythm. Physiol Res 58: 219-228, 2009

24 Touma C, Palme R and Sachser N: Analyzing corticosterone metabolites in fecal samples of mice: a noninvasive technique to monitor stress hormones. Hormones and Behavior 45: 10-22, 2004. 